\title{
Social Influences on Song Learning
}

\author{
Authors: Iva Ljubičici ${ }^{1,2}$, Julia Hyland Bruno ${ }^{1,3} \&$ Ofer Tchernichovski ${ }^{1}$ \\ ${ }^{1}$ Department of Psychology, Hunter College, City University of New York, NY \\ ${ }^{2}$ Department of Biology, Graduate Center, City University of New York, NY \\ ${ }^{3}$ Department of Psychology, Graduate Center, City University of New York, NY
}

Corresponding author: Ofer Tchernichovski (Tchernichovski@gmail.com)

\begin{abstract}
Social animals must learn during development how to integrate successfully into their group. In vocal learners such as songbirds and humans, the development of vocal communication is initially guided by social interactions with the parents. Later on, vocal development is further shaped through interactions with peers and by attending to the consequences of others interacting. It is difficult to assess, however, how social forces combine to shape the outcomes of vocal development. We first review technical advances that make it possible to track social influences on vocal development in songbirds. We then outline methods for simulating social environments of vocal learning. Such virtual environments would present birds with interactive scenarios in order to directly assess social influences over developmental time scales.
\end{abstract}

\section{Introduction}

In most animal species, only a fraction of juveniles survive to maturity. In addition to being small, inexperienced, and vulnerable, young social animals must also learn how to successfully integrate within their group. They must learn how to identify and interact with friends and enemies [1,2], and how to utilize public and private space [3]. In vocal learners such as songbirds and humans, juveniles must also learn complex vocal communication skills, which are often initially shaped by social interactions with parents. Later, social learning continues not only through direct (potentially agonistic) interactions with peers but also by attending to the consequences of interactions between others (Fig. 1). The complexity of these factors, and the long duration of vocal development, make it difficult to assess how social forces combine to shape the outcomes of vocal development [4].

In humans, even two-day-old infants prefer to listen to infant-directed speech [5], which is higher in pitch, simplified in grammar, and slower overall [6]. These manipulations facilitate word recognition [7] and segmentation [8] by infants. The timing of vocal exchanges with the caregiver is particularly important: nine-month-old infants can quickly match the phonological structure of their mother's vocalizations, but only if she answers their babbling promptly [9]. 
Similar influences have been observed in songbirds: juvenile zebra finches produce poor imitation of non-interactive song playbacks, but copy live tutors with high accuracy $[10,11]$. Vocal development in songbirds is also susceptible to complex social interactions with peers and adults other than parents $[12,13]$. There is a large diversity of song learning strategies across songbird species: there are differences in the timing and speed of learning, repertoire size, and the degree of imitation [14]. Here we focus on songbirds that are age-limited learners, where social influences occur within a narrow developmental window $[14,15]$, making it feasible to track an entire vocal development under controlled conditions [16,17]. We review recent technical advances for quantifying the cumulative influences of social factors on vocal development. We start with techniques for tracking vocal interactions, non-vocal communication, and eavesdropping. We then present a framework for a more ambitious approach of experimenting with virtual social environments (VSE), in order to test the influence of specific social variables and potential synergies between them. If successful, VSEs could test a broad range of hypotheses about how songbirds interpret and incorporate social information during vocal development.

\section{Social influences on vocal development}

The social environment can potentially shape the course of vocal development in three ways:

Vocal interactions: The role of auditory input on vocal development is much more extensive than merely providing 'sensory templates' for imitation. In humans, turn-taking and overlap avoidance are universal across languages, and minor variations in turn-taking tempo can define cultural identities [18]. At three months old, infants are already attentive to minor temporal delays in interactive episodes with their mothers [19], suggesting that perception of turn-taking rules develops very early. Many animal species, including vocal-non-learners, exhibit antiphonal vocal exchanges. Juvenile marmoset monkeys, for example, learn to avoid call overlap with family members [20*]. It is not known if antiphonal calling affects song development in songbirds, but since juveniles typically exchange thousands of calls with parents and peers every day [21], developmental effects are likely.

Non-vocal communication: Nonverbal maternal responses increase the complexity of an eightmonth-old's speech, but only if these are contingently related [22]. Fourteen-month-olds will turn their head at a pointing gesture, and by 18 months they will use this social cue to learn new words [23]. Non-vocal gestures appear to affect vocal development in songbirds as well, often in subtle ways: female cowbirds, which do not sing, guide juvenile males to produce certain dialects with quick wing strokes or beak gapes [24,25]. Remarkably, lesioning forebrain song nuclei eliminates the female's preferences for high quality songs and generates disruptions within the social network [26**]. In zebra finches, a large array of both affiliative gestures and aggressive interactions, such as preening and feeding or chasing and pecking, appear to correlate with tutor choice $[27,28]$, but controlling for such social influences is challenging.

Eavesdropping: In order to acquire an appropriate vocal repertoire, juveniles need to learn about their surrounding social network. Human infants as young as 18 months can learn new words from overhearing adult conversation [29]. Until recently, the capacity to make social inferences via observation was thought to exist in only a few species of non-human animals, but it now appears that many species of birds also take advantage of eavesdropping to acquire vital social information. For instance, juvenile song sparrows silently eavesdrop on interactions between adult males [30], and often imitate more songs from an adult they hear interacting with another juvenile than one they interacted with directly [31]. Here, the timing of song learning is 
important: adult males only tolerate immature males within their territory, which suggests that opportunities for direct interactions may exist during early learning, while limited to eavesdropping later on [32]. In a laboratory setting, canaries that overheard overlapping songs between two males were less likely to call to the interrupting "winner" male at a later time [33]. This could mean that they perceive and remember dominance in singing interactions. Finally, cowbird females attend to the calling behavior of other females in their flock, producing more copulation displays in response to male songs previously associated with female calls [34]. These findings, however, have limited bearing on whether juvenile songbirds extract information by observing social interactions and how this affects song development.

\section{Tracking social interactions during song development}

Song learning is a means by which an individual establishes its place within a social network. Recent advances in computation power, data storage, and miniaturization of electronic devices have made it possible to study song development continuously [35,36] and even across generations [37], but only in laboratory environments where social interactions are either restricted, or nonexistent. Field studies provide ecological validity, but monitoring vocal development in the wild is usually not feasible. As a result, cultural transmission of birdsong has been studied almost exclusively by sampling mature songs and quantifying population-level vocal changes over time [38,39]. Although it is still prohibitive to study song learning continuously outside of the lab, technologies for tracking individual behavior in social environments are rapidly emerging [40*]. Recently, the spread of new foraging techniques in wild great tits was recently tracked over several weeks, revealing a gradual cultural spread with the emergence of strong conformity to cultural norms [41]. Similar tracking of individuals was used to determine changes in zebra finch social networks due to developmental stress [42] but was limited to identification of birds at feeders and did not track moment-to-moment interactions between individuals within the network. Adopting a similar approach in order to study vocal learning would require continuously recording vocalizations, relative 3D location, heading, and mechanisms for detecting non-vocal gestures:

Tracking vocal interactions: In humans, the LENA system [43] now allows dense sampling of early speech development over several months. Similarly, tracking vocal interactions in small songbirds is now feasible using lightweight wireless microphones [44,45**]. At least in seminatural aviaries in the lab, these techniques now allow for tracking vocal interactions during pairbond formation [46] and could be easily extended to juvenile song development [17].

Tracking relative location and heading: In animals where movement is restricted to twodimensional planes, it is relatively easy to track location and heading of multiple animals in social environments (e.g.: fruit flies [47], mice [48] and fish swimming in shallow waters [49,50*]). GPS has been used to track movement patterns in humans [51] and wild baboons [52], and $3 \mathrm{D}$ image analysis has been used to capture aerial displays in starling flocks [53,54]. In insects, tracking 3D trajectories requires highly controlled environments [55]. To our knowledge, no techniques are currently available for monitoring the 3D moment-to-moment movements of small songbirds in a social environment over the course of song development. However, it is likely that combining the above technologies will make this possible soon.

Tracking non-vocal gestures: Recently, several groups have developed techniques for automatically classifying predefined behaviors, such as social interactions in mice [48] and fruit flies [47], and courtship behavior using 3D body postures in mice [56]). There are both technical 
and conceptual issues inherent in using automated detection of ethologically meaningful gestures. However, even a crude detection of body postures [56] or gaze $[47,54]$ could be useful for studying social effects on song learning.

\section{Toward virtual social environments (VSEs) for studying vocal development}

Continuous monitoring of social interactions is likely to provide deeper understanding of song development. However, establishing causality from such complex longitudinal data is unlikely to succeed unless complemented by controlled studies. We suggest that this can be achieved by developing VSEs that simulate the social context of song learning, through iterative interactions between the developing bird and a computerized visual and vocal interface. Video playbacks have been successfully used to study avian visual communication [58,59], species recognition [60,61], and individual recognition [62,63], though their use in song learning has been limited [64]. Accurate color rendition is a concern because of species differences in color sensitivity $[65,66]$, but some bird species can nevertheless discriminate between individuals on regular computer screens $[62,63]$.

If successful, virtual reality experiments could potentially combine ecological validity with experimental control [67]. One of the most successful virtual environments for studying animal behavior is the drosophila "flight simulator" $[68,69]$. In these experiments, a fruit fly is suspended, tethered to a tiny rod. As the fly attempts to move, forces generated by its wings feed back to an interface that moves and rotates a surrounding display image in a manner that simulates active navigation flight. Similar approaches were recently used in the mouse [70,71*] and in humans [72]. Once established, such virtual reality scenarios can bypass physical and biological constraints: fundamental questions about spatial learning may be tested by controlling how movement affects perspective in virtual spatial navigation tasks [71]. We propose trying a similar approach to the study of social influences on vocal learning, specifically at the level of direct social interactions, eavesdropping, and statistical learning.

Simulating social interactions: In a VSE, the relative contributions of different sensory information to song learning may be titrated in a controlled manner. In our lab, we are now testing if the orientation of a virtual adult tutor (Fig. 2A) may affect the juvenile's late-stage developing song. Our preliminary results show that birds quickly shifted pitch to match the song of a virtual male that appeared to be singing towards them (Fig. 2B). We plan to use the data from these non-contingent virtual scenarios to establish a baseline for more complex VSEs, where visual and auditory stimuli are interactive [73].

Simulating eavesdropping scenarios: One of the most exciting questions that VSEs may answer is how, and at what level, a juvenile bird can learn to incorporate observed social information into its song. For example, to what extent can a bird derive social rules from observing aggressive interactions? Suppose that bird A displaces bird B, but bird B displaces bird C: will the juvenile observer infer a linear hierarchy from those pairwise interactions [74], and use this information to alter its developing song? Such an inference could affect moment-to-moment behavior (e.g., deciding which virtual bird to approach or exchange calls with [33]) as well as developmental trajectories related to tutor choice and song convergence or divergence within the peer group.

Simulating statistical learning scenarios: Human infants can perceive statistical regularities in spoken language very early [75], which helps them to segment spoken language into words and 
sentences [76]. It is unknown to what extent songbirds acquire and use statistical information in the context of vocal development. At the simplest level, one might ask if social birds can keep track of the individuals around them, and relate this information to their own actions. For example, imagine a VSE where natural variations in song structure become contingent upon dynamic changes in the sex ratio of bird images presented: will the juvenile perceive this contingency and alter its song so as to attract more females (Fig. 3)? If successful, tracking vocal changes this way would reveal which statistical rules are most effective in dynamically inducing vocal changes. Similar approaches could be developed for testing sensitivity to spatial and contextual rules of singing behavior.

\section{Conclusions}

A major appeal of studying birdsong is the fact that, like human language, it is culturally transmitted. Figuring out how social processes accumulate to shape vocal learning in songbirds is within reach. In this review we highlighted three categories of social factors that are likely to play a role in vocal development in both humans and songbirds: vocal interactions, non-vocal communication, and eavesdropping as means of acquiring pragmatic information about the social world. We suggest that these factors may modulate sensorimotor learning mechanisms that are well understood in songbirds, through many development studies [77]. Designing VSEs to test specific hypotheses about social influences on vocal learning could provide an inroad into the ecological complexity of vocal development without sacrificing experimental control.

\section{Acknowledgments:}

We thank Petra Ljubičić and Kirsten Canfield for the use of their artwork. Supported by NSF grant 1261872 to OT.

\section{References}

1. Nowak MA: Five rules for the evolution of cooperation. Science 2006, 314:1560-1563.

2. Rubenstein DR, Wrangham R (Eds): Ecological Aspects of Social Evolution: Birds and Mammals. Princeton University Press; 1987.

3. Markham AC, Guttal V, Alberts SC, Altmann J: When good neighbors don't need fences: Temporal landscape partitioning among baboon social groups. Behav. Ecol. Sociobiol. 2013, 67:875-884.

4. Warlaumont AS, Oller DK, Dale R, Richards JA, Gilkerson J, Xu D: Vocal Interaction Dynamics of Children With and Without Autism. In Proceedings of the 32nd Annual Conference of the Cognitive Science Society. Edited by Ohlsson S, Catrambone R. Cognitive Science Society; 2010:121-126.

5. Cooper RP, Aslin RN: Preference for Infant-Directed Speech in the First Month after Birth. Child Dev. 1990, 61:1584-1595.

6. Kuhl PK, Andruski JE, Chistovich IA, Chistovich LA, Kozhevnikova E V, Ryskina VL, Stolyarova EI, Sundberg U, Lacerda F: Cross-Language Analysis of Phonetic Units in Language Addressed to Infants. Science 1997, 277:684-686.

7. Singh L, Nestor S, Parikh C, Yull A: Influences of Infant-Directed Speech on Early Word Recognition. Infancy 2009, 14:654-666.

8. Thiessen ED, Hill EA, Saffran JR: Infant-Directed Speech Facilitates Word Segmentation. Infancy 2005, 7:53-71.

9. Goldstein MH, Schwade JA: Social Feedback to Infants' Babbling Facilitates Rapid Phonological Learning. Psychol. Sci. 2008, 19:515-23. 
10. Eales L: The Influences of Visual and Vocal Interaction on Song Learning in Zebra finches. Anim. Behav. 1989, 37:507-508.

11. Derégnaucourt S, Poirier C, Kant A Van Der, Linden A Van Der, Gahr M: Comparisons of different methods to train a young zebra finch (Taeniopygia guttata) to learn a song. J. Physiol. Paris 2013, 107:210-8.

12. Derégnaucourt S, Gahr M: Horizontal transmission of the father's song in the zebra finch (Taeniopygia guttata). Biol. Lett. 2013, 9.

13. Soma MF: Social Factors in Song Learning: A Review of Estrildid Finch Research. Ornithol. Sci. 2011, 10:89-100.

14. Beecher MD, Brenowitz E a: Functional aspects of song learning in songbirds. Trends Ecol. Evol. 2005, 20:143-9.

15. Brainard MS, Doupe AJ: What songbirds teach us about learning. Nature 2002, 417:351-358.

16. Tchernichovski O, Lints TJ, Deregnaucourt S, Cimenser A, Mitra PP: Studying the song development process: rationale and methods. Ann. N. Y. Acad. Sci. 2004, 1016:348-63.

17. Lipkind D, Tchernichovski O: Quantification of developmental birdsong learning from the subsyllabic scale to cultural evolution. Proc. Natl. Acad. Sci. 2011, 108:15572-15579.

18. Stivers T, Enfield NJ, Brown P, Englert C, Hayashi M, Heinemann T, Hoymann G, Rossano F, de Ruiter JP, Yoon K-E, et al.: Universals and cultural variation in turn-taking in conversation. Proc. Natl. Acad. Sci. U. S. A. 2009, 106:10587-10592.

19. Striano T, Henning A, Stahl D: Sensitivity to interpersonal timing at 3 and 6 months of age. Interact. Stud. 2006, 7:251-271.

20. Chow CP, Mitchell JF, Miller CT, Miller CT: Vocal turn-taking in a non-human primate is learned during ontogeny. Proc. R. Soc. B Biol. Sci. 2015, 282: 20150069.

* While marmoset monkeys do not learn their calls, this study shows they learn to avoid call overlap through errors made from call interactions with their parents. Interestingly, social context affects the tempo of turntaking, suggesting that juvenile marmosets do not generalize rules across individuals.

21. Elie JE, Soula HA, Mathevon N, Vignal C: Dynamics of communal vocalizations in a social songbird, the zebra finch (Taeniopygia guttata). J. Acoust. Soc. Am. 2011, 129:4037-46.

22. Goldstein MH, King AP, West MJ: Social interaction shapes babbling: Testing parallels between birdsong and speech. Proc. Natl. Acad. Sci. 2003, 100:8030-8035.

23. Briganti AM, Cohen LB: Examining the role of social cues in early word learning. Infant Behav. Dev. 2011, 34:211-214.

24. West MJ, King AP: Female visual displays affect the development of male song in the cowbird. Nature 1988, 334:244-246.

25. King AP, West MJ, Goldstein MH: Non-vocal shaping of avian song development: parallels to human speech development. Ethology 2005, 111:101-118.

26. Maguire SE, Schmidt MF, White DJ: Social brains in context: lesions targeted to the song control system in female cowbirds affect their social network. PLoS One 2013, 8:e63239.

** This study showed that removing the song system in female cowbirds, which do not sing, eliminated their selectivity towards higher quality male songs. This weakened the pair-bond with their mate, increased overall female-female competition within the group, and disrupted male dominance hierarchies. This illustrates how small changes in an individual's behavior can have cascading effects on social group dynamics.

27. Jones AE, Slater PJB: The role of Aggression in song tutor choice in the zebra finch: Cause or effect? Behaviour 1996, 133.

28. Williams H: Models for song learning in the zebra finch: fathers or others? Anim. Behav. 1990, 39:745757. 
29. Floor P, Akhtar N: Can 18-Month-Old Infants Learn Words by Listening In on Conversations? Infancy 2006, 9:327-339.

30. Templeton CN, Akçay C, Campbell SE, Beecher MD: Juvenile sparrows preferentially eavesdrop on adult song interactions. Proc. Biol. Sci. 2010, 277:447-453.

31. Beecher M, Burt J, Ologhlen A, Templeton C, Campbell S: Bird song learning in an eavesdropping context. Anim. Behav. 2007, 73:929-935.

32. Templeton CN, Campbell SE, Beecher MD: Territorial song sparrows tolerate juveniles during the early song-learning phase. Behav. Ecol. 2012, 23:916-923.

33. Amy M, Leboucher G: Effects of eavesdropping on subsequent signalling behaviours in male canaries. Ethology 2009, 115:239-246.

34. Freed-Brown G, White DJ: Acoustic mate copying: female cowbirds attend to other females' vocalizations to modify their song preferences. Proc. Biol. Sci. 2009, 276:3319-3325.

35. Derégnaucourt S, Mitra PP, Fehér O, Pytte C, Tchernichovski O: How sleep affects the developmental learning of bird song. Nature 2005, 433:710-6.

36. Lipkind D, Marcus GF, Bemis DK, Sasahara K, Jacoby N, Takahasi M, Suzuki K, Feher O, Ravbar P, Okanoya K, et al.: Stepwise acquisition of vocal combinatorial capacity in songbirds and human infants. Nature 2013, 498:104-108.

37. Fehér O, Wang H, Saar S, Mitra PP, Tchernichovski O: De novo establishment of wild-type song culture in the zebra finch. Nature 2009, 459:564-8.

38. Goodale E, Podos J: Persistence of song types in Darwin's finches, Geospiza fortis, over four decades. Biol. Lett. 2010, 6:589-592.

39. Williams H, Levin II, Norris DR, Newman AEM, Wheelwright NT: Three decades of cultural evolution in Savannah sparrow songs. Anim. Behav. 2013, 85:213-223.

40. Dell AI, Bender J a., Branson K, Couzin ID, de Polavieja GG, Noldus LPJJ, Pérez-Escudero A, Perona P, Straw AD, Wikelski M, et al.: Automated image-based tracking and its application in ecology. Trends Ecol. Evol. 2014, 29:417-428.

* A great review that emphasizes the power of automated image-based tracking to not only identify individuals, but also their behaviors. It includes a key list of existing software that can track individuals in the lab and in the field.

41. Aplin LM, Farine DR, Cockburn A, Thornton A, Sheldon BC: Experimentally induced innovations lead to persistent culture via conformity in wild birds. Nature $2015, \mathbf{5 1 8}: 538-541$.

42. Boogert NJ, Farine DR, Spencer KA: Developmental stress predicts social network position. Biol. Lett. 2014, 10:20140561.

43. $\mathrm{Xu} \mathrm{D}$, Yapanel U, Gray S: Reliability of the LENA ${ }^{T M}$ language environment analysis system in young children's natural home environment. 2009.

44. Anisimov VN, Herbst JA, Abramchuk AN, Latanov A V, Hahnloser RHR, Vyssotski AL: Reconstruction of vocal interactions in a group of small songbirds. Nat. Methods 2014, 11:1135-7.

45. Ter Maat A, Trost L, Sagunsky H, Seltmann S, Gahr M: Zebra finch mates use their forebrain song system in unlearned call communication. PLoS One 2014, 9:e109334.

** This study, which reports a novel function for the avian song system, includes a detailed description of new lightweight wireless sound recording technology that enables continuous audio tracking in songbirds for up to two weeks (and may also be combined with electrophysiology).

46. Gill LF, Goymann W, Ter Maat A, Gahr M: Patterns of call communication between group-housed zebra finches change during the breeding cycle. Elife 2015, 4:1-23.

47. Branson K, Robie AA, Bender J, Perona P, Dickinson MH: High-throughput ethomics in large groups of Drosophila. Nat. Methods 2009, 6:451-7.

48. de Chaumont F, Coura RD-S, Serreau P, Cressant A, Chabout J, Granon S, Olivo-Marin J-C: Computerized video analysis of social interactions in mice. Nat. Methods 2012, 9:410-417. 
49. Katz Y, Tunstrom K, Ioannou CC, Huepe C, Couzin ID: Inferring the structure and dynamics of interactions in schooling fish. Proc. Natl. Acad. Sci. 2011, 108:18720-18725.

50. Rosenthal SB, Twomey CR, Hartnett AT, Wu HS, Couzin ID: Revealing the hidden networks of interaction in mobile animal groups allows prediction of complex behavioral contagion. Proc. Natl. Acad. Sci. 2015, 112:201420068.

* This study used automated tracking of location, body posture, and eye gaze in a large school of fish to build interaction networks and predict social influences on decision making.

51. González MC, Hidalgo CA, Barabási A-L: Understanding individual human mobility patterns. Nature 2008, 453:779-782.

52. Strandburg-Peshkin A, Farine DR, Couzin ID, Crofoot MC: Shared decision-making drives collective movement in wild baboons. Science 2015, 348:1358-1361.

53. Cavagna A, Cimarelli A, Giardina I, Parisi G, Santagati R, Stefanini F, Viale M: Scale-free correlations in starling flocks. Proc. Natl. Acad. Sci. U. S. A. 2010, 107:11865-11870.

54. Bialek W, Cavagna A, Giardina I, Mora T, Silvestri E, Viale M, Walczak AM: Statistical mechanics for natural flocks of birds. 2011, doi:10.1073/pnas.1118633109.

55. Mischiati M, Lin H, Herold P, Imler E, Olberg R, Leonardo A: Internal models direct dragonfly interception steering. Nature 2014, 517:333-338.

56. Matsumoto J, Urakawa S, Takamura Y, Malcher-Lopes R, Hori E, Tomaz C, Ono T, Nishijo H: A 3DVideo-Based Computerized Analysis of Social and Sexual Interactions in Rats. PLoS One 2013, 8:e78460.

57. Butler SR, Fernández-Juricic E: European starlings recognize the location of robotic conspecific attention. Biol. Lett. 2014, 10.

58. Evans CS, Marler P: On the use of video images as social stimuli in birds: audience effects on alarm calling. Anim. Behav. 1991, 41:17-26.

59. Partan S, Yelda S, Price V, Shimizu T: Female pigeons, Columba livia, respond to multisensory audio/video playbacks of male courtship behaviour. Anim. Behav. 2005, 70:957-966.

60. Adret P: Discrimination of video images by zebra finches (Taeniopygia guttata): Direct evidence from song performance. J. Comp. Psychol. 1997, 111:115-125.

61. Galoch Z, Bischof H-J: Behavioural responses to video playbacks by zebra finch males. Behav. Processes 2006, 74:21-6.

62. Galoch Z, Bischof H-J: Zebra Finches actively choose between live images of conspecifics. Ornithol. Sci. 2006, 5:57-64.

63. Bird CD, Emery $\mathrm{NJ}$ : Using video playback to investigate the social preferences of rooks, Corvus frugilegus. Anim. Behav. 2008, 76:679-687.

64. Deshpande M, Pirlepesov F, Lints T: Rapid encoding of an internal model for imitative learning. Proc. Biol. Sci. 2014, 281:20132630.

65. Cuthill IC, Hart NS, Partridge JC, Bennett a. TD, Hunt S, Church SC: Avian colour vision and avian video playback experiments. Acta Ethol. 2000, 3:29-37.

66. Fleishman LJ, Endler $\mathrm{J}$ a.: Some comments on visual perception and the use of video playback in animal behavior studies. Acta Ethol. 2000, 3:15-27.

67. Bohil CJ, Alicea B, Biocca FA: Virtual reality in neuroscience research and therapy. Nat. Rev. Neurosci. 2011, 12:1-2.

68. Wasserman SM, Aptekar JW, Lu P, Nguyen J, Wang AL, Keles MF, Grygoruk A, Krantz DE, Larsen C, Frye MA: Olfactory neuromodulation of motion vision circuitry in Drosophila. Curr. Biol. 2015, 25:467-72.

69. Brembs B: The Operant and the Classical in Conditioned Orientation of Drosophila melanogaster at the Flight Simulator. Learn. Mem. 2000, 7:104-115.

70. Harvey CD, Collman F, Dombeck DA, Tank DW: Intracellular dynamics of hippocampal place cells 
during virtual navigation. Nature 2009, 461:941-6.

71. Chen G, King JA, Burgess N, O'Keefe J: How vision and movement combine in the hippocampal place code. Proc. Natl. Acad. Sci. U. S. A. 2013, 110:378-83.

* In this study, a virtual reality set-up for mice was used to dissociate the contributions of environmental vs. self-generated motion cues to the hippocampal 'cognitive map.'

72. Ekstrom AD, Caplan JB, Ho E, Shattuck K, Fried I, Kahana MJ: Human hippocampal theta activity during virtual navigation. Hippocampus 2005, 15:881-9.

73. King SL: You talkin' to me? Interactive playback is a powerful yet underused tool in animal communication research. Biol. Lett. 2015, 11:20150403.

74. Rose GJ, Goller F, Gritton HJ, Plamondon SL, Baugh AT, Cooper BG: Species-typical songs in whitecrowned sparrows tutored with only phrase pairs. Nature 2004, 432:753-8.

75. Marcus GF, Vijayan S, Bandi Rao S, Vishton PM: Rule learning by seven-month-old infants. Science 1999, 283:77-80.

76. Jusczyk PW: The Discovery of Spoken Language. MIT Press; 2000.

77. Okubo TS, Mackevicius EL, Payne HL, Lynch GF, Fee MS: Article Growth and splitting of neural sequences in songbird vocal development. Nature 2015.

\section{FIGURE LEGENDS}

FIGURE 1. Vocal development may be influenced by many social experiences. These include direct vocal and non-vocal interactions, and observed or overheard interactions between others. At any point in developmental time, these influences can have varying effects as the bird's social networks increase in complexity.

FIGURE 2. Virtual Social Environments (VSEs) can be used to isolate the effects of specific social and visual variables on song development. In this example we test if songs that are directed at a juvenile are more influential than songs that are not directed toward him. a) We first used operant playbacks to train young zebra finches to imitate playbacks of a 3-syllable song (ABC). Once birds had produced recognizable song copies, but before the end of the sensitive period [36], we placed each bird in a virtual social environment where one video displayed a virtual tutor singing towards the pupil, while the other video showed a second virtual tutor, who appeared to be singing away from the pupil. We altered the pitch of one syllable to be either slightly higher $(\mathrm{ABC}+)$ in one virtual tutor, or lower $(\mathrm{ABC}-)$ in the second one. b) Developmental trajectories of two birds show that birds can quickly adopt a song variant based on visual features. Recording the entire vocal behavior of the bird enables us to detect the exact moment where vocal changes occurred [17]. Each line in the plot represents one song motif. Red arrows indicate the onset of VSE training. The pitch of the $\mathrm{C}$ syllable is outlined in color. Left: pitch decreases, to match $\mathrm{ABC}$ - song of a virtual tutor singing facing the bird. Right: pitch increase, to match $\mathrm{ABC}+$ song of a virtual tutor singing facing the bird.

FIGURE 3. Virtual Social Environments can be designed to test how developing songbirds use statistical rules to guide vocal learning. Here, the VSE changes dynamically via real time pitch detection. As the bird sings, the pitch of his song alters the ratio of virtual females to males facing him, allowing us to test if the bird will perceive this contingency and adjust his song to attract more females. 


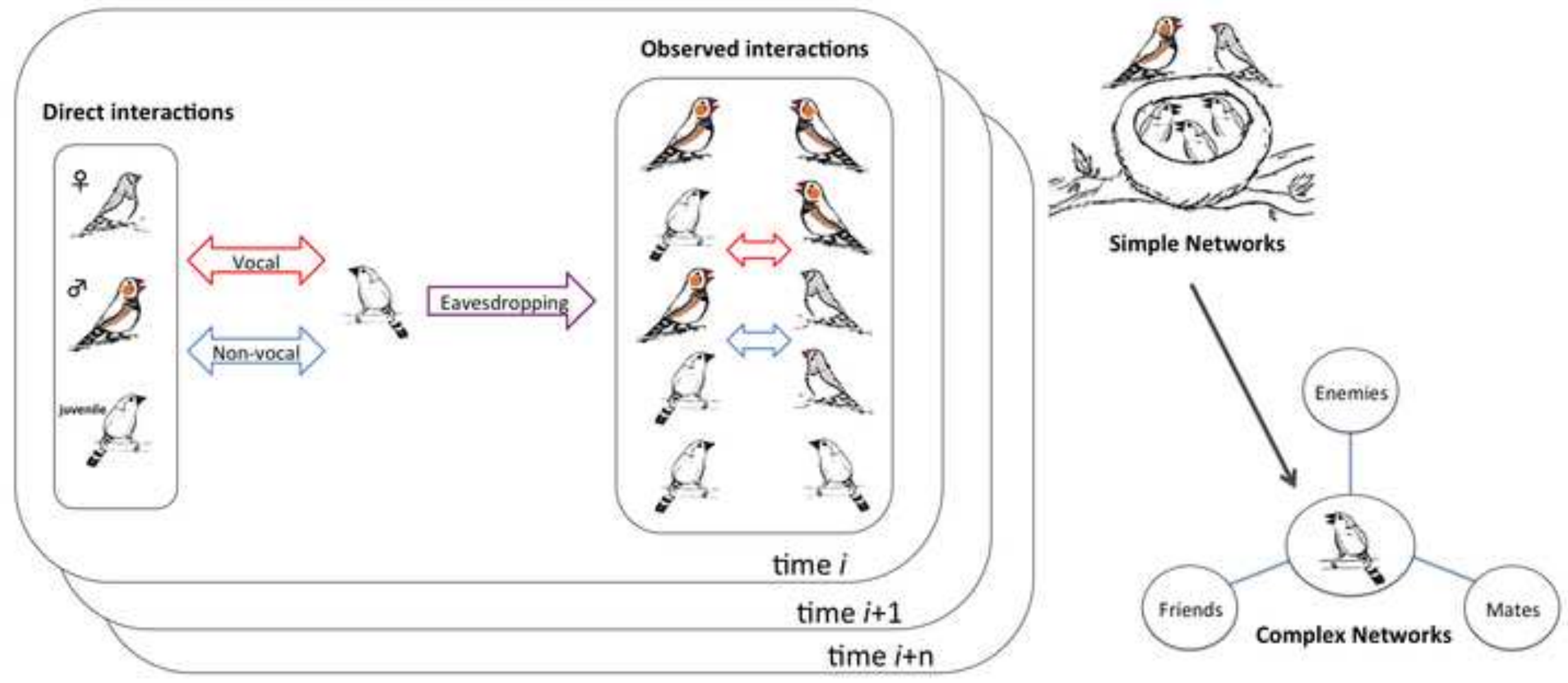


(a)

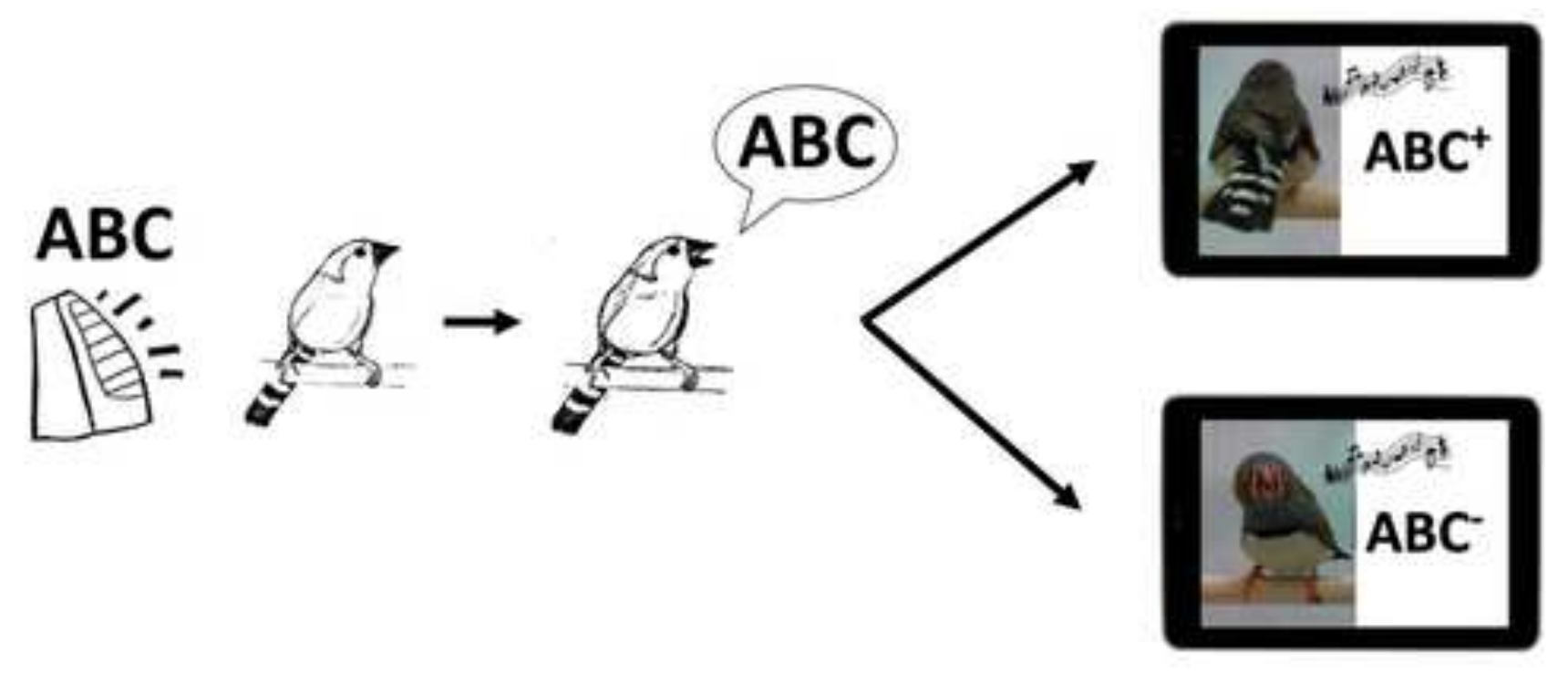

Figure 2

(b)
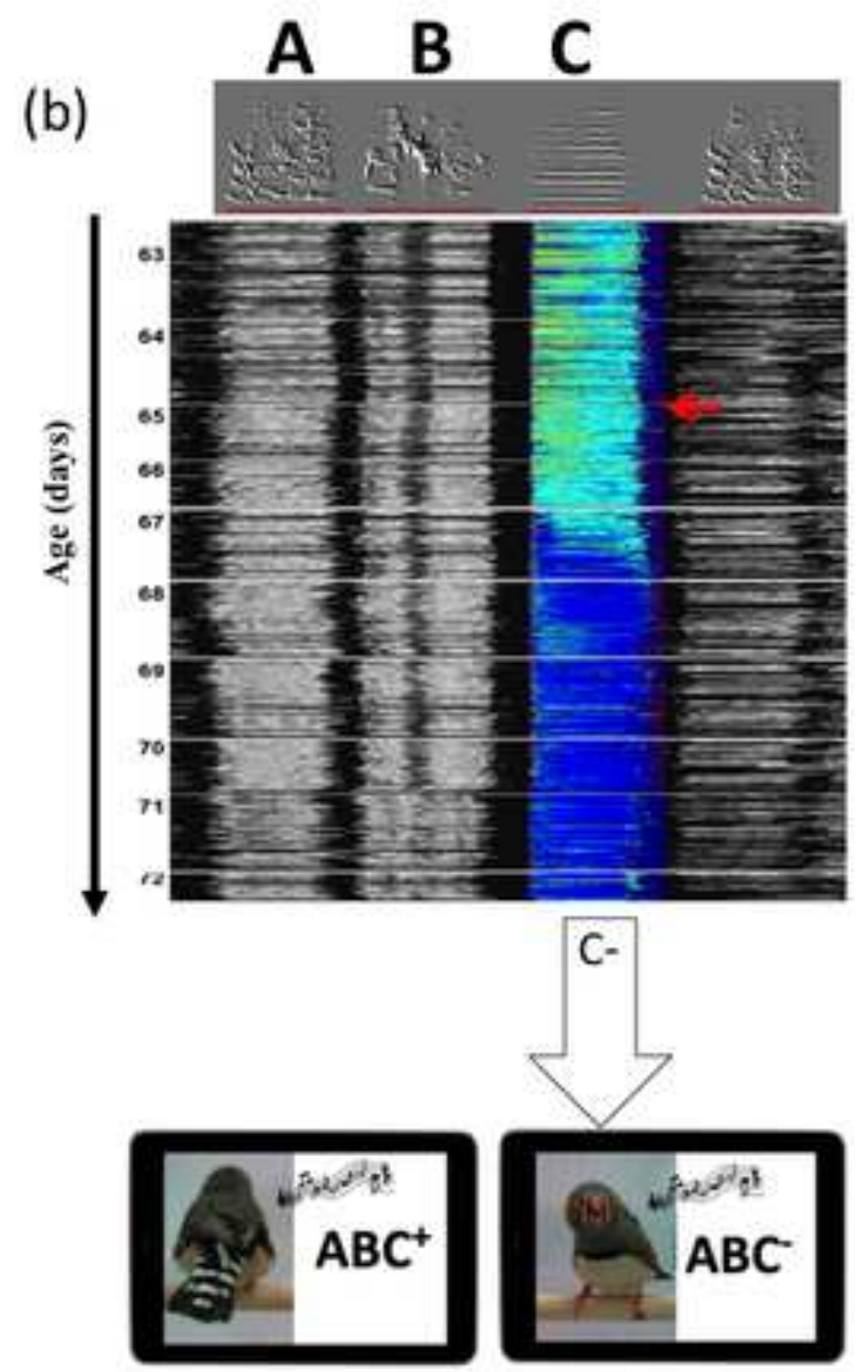

A B C

$\mathrm{ABC}^{+}$

ABC

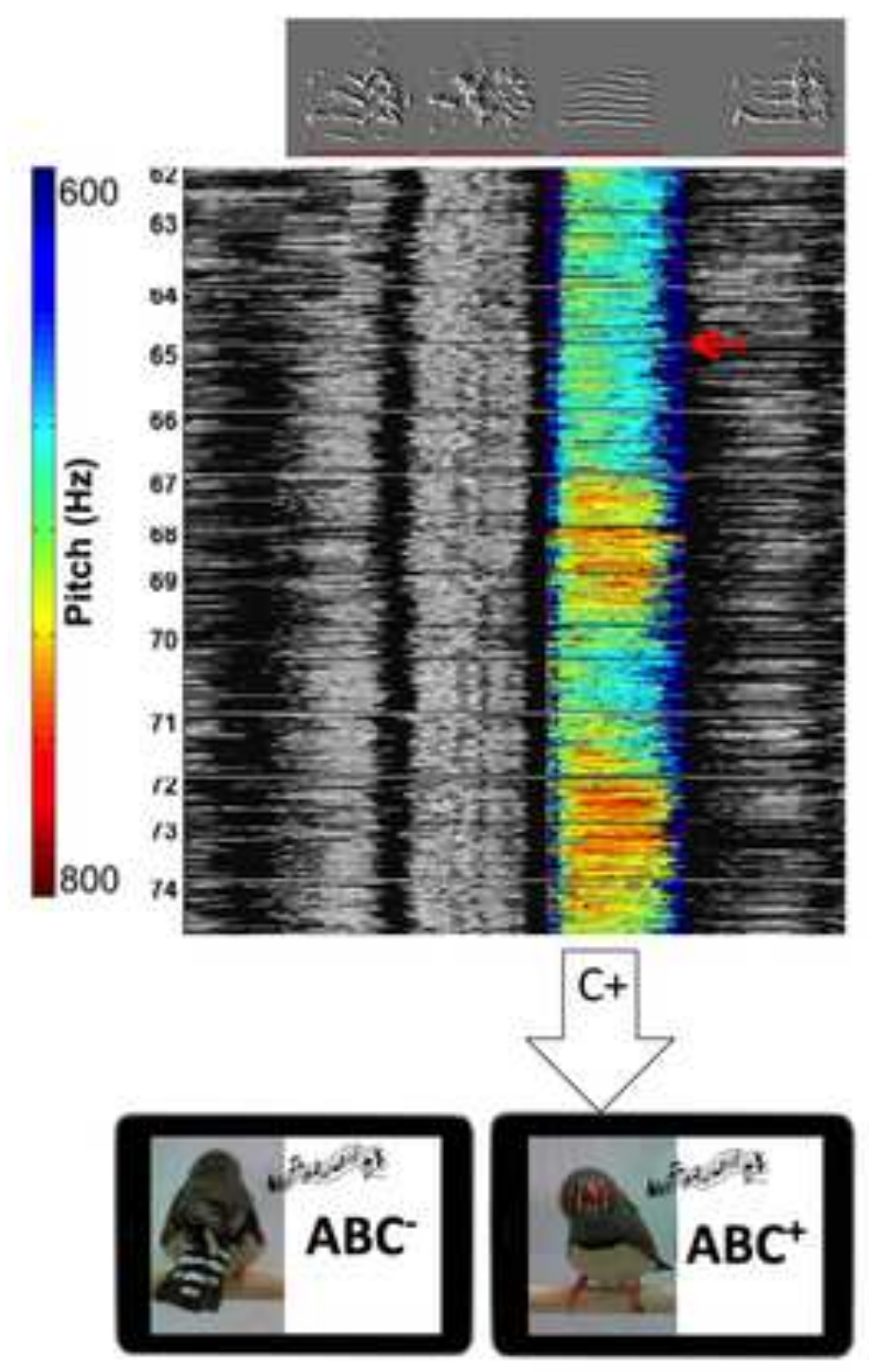




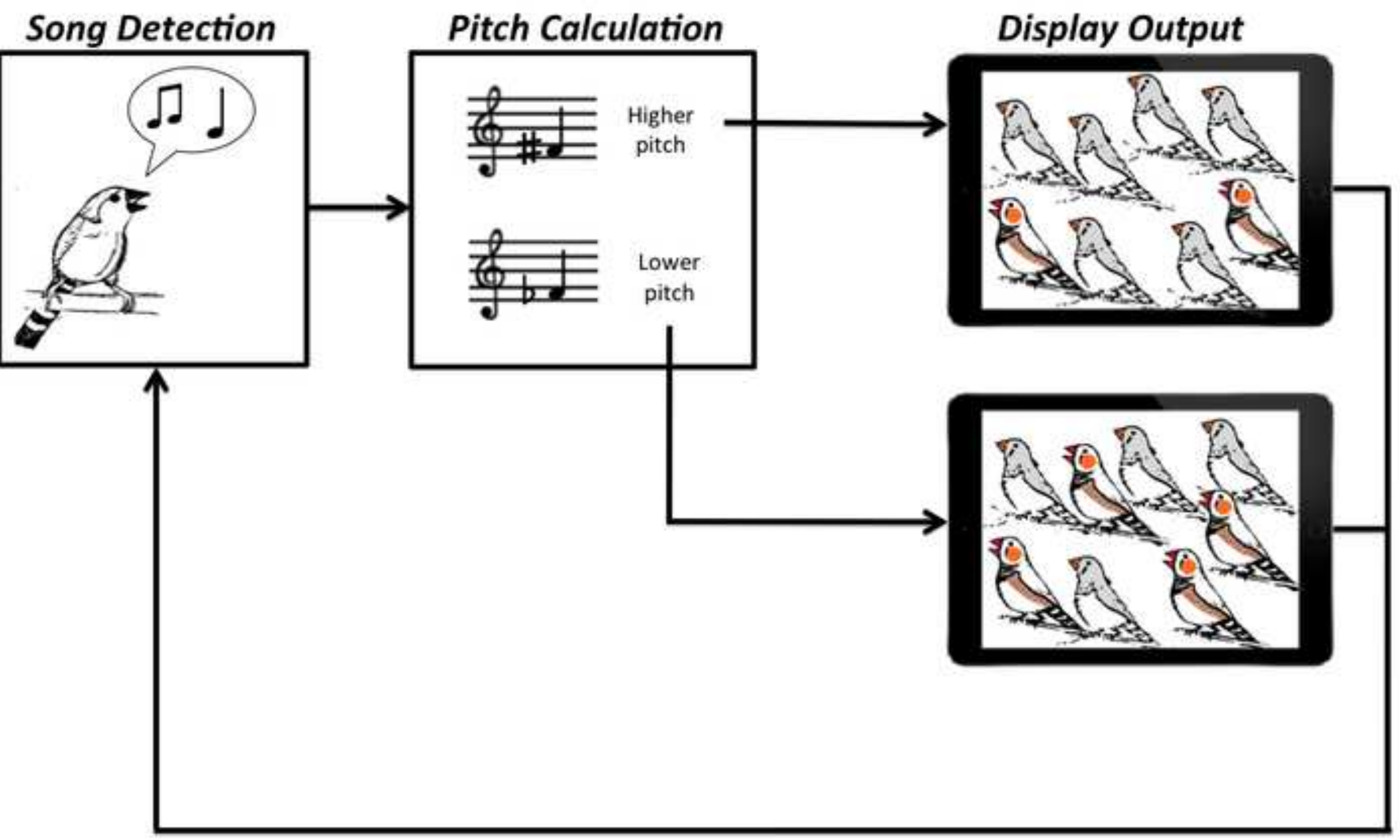

